Article

\title{
Element Segregation and Electrical Properties of PMN-32PT Grown Using the Bridgman Method
}

\author{
Sijia Wang ${ }^{1,2}$, Zengzhe $\mathrm{Xi}^{1,2,3, *}$, Pinyang Fang ${ }^{2,3}$, Xiaojuan $\mathrm{Li}^{2,3}$, Wei Long ${ }^{2,3}$ and Aiguo $\mathrm{He}^{2,3}$ \\ 1 School of Science, Xi'an Technological University, Xi'an 710021, China; cigawang1231@163.com \\ 2 Shaanxi Key Laboratory of Photoelectric Functional Materials and Devices, Xi'an 710021, China; \\ fpy_2000@163.com (P.F.); lixiaojuan28@163.com (X.L.); longwei@xatu.com (W.L.); \\ 5129226701@163.com (A.H.) \\ 3 School of Materials and Chemical Engineering, Xi'an Technological University, Xi'an 710021, China \\ * Correspondence: zzhxi@xatu.edu.cn; Tel.: +86-29-86173324
}

Received: 5 January 2019; Accepted: 13 February 2019; Published: 15 February 2019

check for updates

\begin{abstract}
A single crystal with nominal composition $\mathrm{Pb}\left(\mathrm{Mg}_{1 / 3} \mathrm{Nb}_{2 / 3}\right) \mathrm{O}_{3}-32 \mathrm{PbTiO}_{3}(\mathrm{PMN} 32 \mathrm{PT})$ was grown by the Bridgman technique. Crystal orientation was determined using the rotating orientation $X$-ray diffraction (RO-XRD). Element distribution was measured along different directions using inductively coupled plasma-mass spectrometry (ICP-MS). The effect of the element segregation along axial and radial directions on the electrical properties of the PMN-32PT crystal was investigated. It is indicated that the electrical properties of the samples along the axial direction were strongly dependent on the PT $\left(\mathrm{PbTiO}_{3}\right)$ content. With the increase of the PT content, the piezoelectric coefficient and remnant polarization were improved. Differently, the electrical properties of the samples along the radial direction were mainly determined by the ratio of the $\mathrm{Nb}$ and $\mathrm{Mg}$. The reasons for the element segregation and electrical properties varied with the composition were discussed.
\end{abstract}

Keywords: PMN-32PT; characterization; segregation; Bridgman technique; ferroelectric materials

\section{Introduction}

Relaxor-based ferroelectric single crystals $\mathrm{Pb}\left(\mathrm{Mg}_{1 / 3} \mathrm{Nb}_{2 / 3}\right) \mathrm{O}_{3}-\mathrm{PbTiO}_{3}(\mathrm{PMN}-\mathrm{PT})$ have an ultrahigh piezoelectric coefficient $\left(d_{33}>2500 \mathrm{pC} / \mathrm{N}\right)$, an electromechanical coupling factor $\left(k_{33}>0.95\right)$, and a low dielectric loss compared to traditional piezoelectric ceramics [1-5]. Based on these superior properties, PMN-PT single crystals are usually considered promising materials in sensors, ultrasonic transducers, and motors applications [6-9].

Large sized PMN-PT single crystals are grown mainly using the Bridgman technique [10-12]. Based on this technique, researchers have further managed to improve the di/piezoelectric properties of the PMN-PT system through some effective ways [13-17]. Hu et al. [18] verified that the high-temperature poling technique was contributed to the enhanced piezoelectric properties. Recently, it was discovered that the optical properties could be induced by rare-earth ions doping in the PMN-PT system [19,20]. Xi et al. [21] confirmed that the specific absorption at the UV-VIS-NIR band and the strong green and red up-conversion photoluminescence (UC PL) under $980 \mathrm{~nm}$ laser excitation were observed in the $\mathrm{Er}^{3+}$ - and $\mathrm{Er}^{3+} / \mathrm{Yb}^{3+}$-modified $\mathrm{Pb}\left(\mathrm{Sc}_{1 / 2} \mathrm{Nb}_{1 / 2}\right) \mathrm{O}_{3}-\mathrm{Pb}\left(\mathrm{Mg}_{1 / 3} \mathrm{Nb}_{2 / 3}\right) \mathrm{O}_{3}-\mathrm{PbTiO}_{3}$ (PSN-PMN-PT) crystals using the flux method. For the Bridgman technique, it is confirmed that the element segregation exists in the single crystals and the electrical properties of the single crystals are strongly dependent on the compositions [22-24]. These results indicate that the element segregation occurred during the growth of the PMN-PT single crystals, and the segregation of PT led to inhomogeneity in electrical properties along the axial direction. Unfortunately, the element 
segregation along the radial direction and the reasons for the $\mathrm{Nb}$ and $\mathrm{Mg}$ segregation of the PMN-PT single crystals using the Bridgman technique was rarely reported in the literature.

In this study, the single crystal with nominal compositional PMN-32PT was grown by the Bridgman technique. The element distribution along the axial and radial directions was confirmed by the inductively coupled plasma-mass spectrometry (ICP-MS). The effect of the element segregation along the axial and radial direction on the electrical properties of the PMN-32PT crystals was investigated. The reasons that the element segregation and electrical properties varied with the composition along the axial direction were also discussed.

\section{Experimental Procedure}

A PMN-32PT single crystal (Ø25 mm) was grown by the Bridgman method (Figure 1a). The crystal was faint yellow with good transparency. Some stress-induced cracks were presented on the top of the crystal. A sheet with a thickness of $0.8 \mathrm{~mm}$ was cut from the as-grown crystal boule along the axial direction (Figure 1b), which showed a poor uniformity in color. The sheet was divided along axial and radial directions with a size of $2 \times 2 \mathrm{~mm}$. The specimens were named as test points from Y1 to $\mathrm{Y} 15$ along the axial direction and test points from $\mathrm{X} 1$ to $\mathrm{X} 4$ along the radial direction. The $\mathrm{Y} 9$ and $\mathrm{X} 4$ test points were the same (shown in Figure 2).

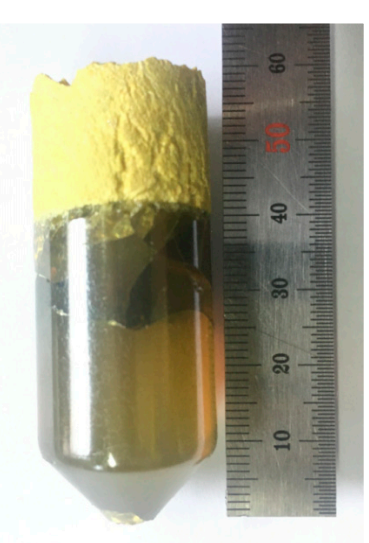

(a)

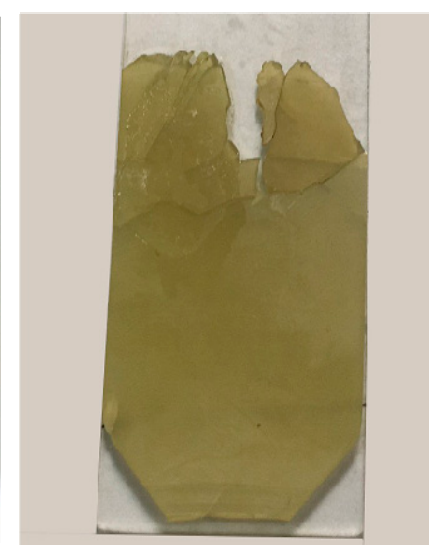

(b)

Figure 1. The as-grown PMN-32PT single crystal and its axial section: (a) the as-grown PMN-32PT single crystal; (b) the axial section along the length of the crystal.

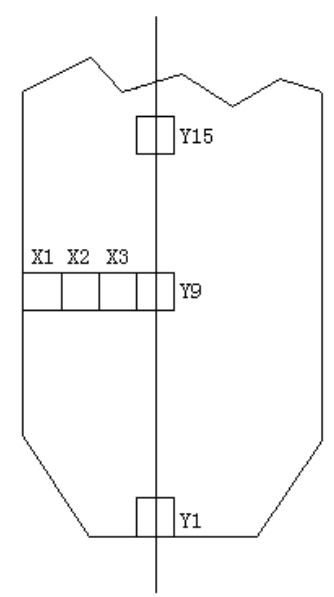

Figure 2. A sketch of specimen cutting.

The orientation of the single crystal was analyzed using rotating orientation X-ray diffraction (RO-XRD) (D/max-2550, Rigaku Corporation, Tokyo, Japan, 2004). Before the electrical property 
measurements, the obtained specimens were annealed at $300{ }^{\circ} \mathrm{C}$ for $1.5 \mathrm{~h}$ to eliminate stress. Silver paste was used to cover the two faces of the crystal sample that were used as electrodes. The dielectric properties were measured using an impedance analyzer (Agilent 4294A, Agilent Technologies Inc., Santa Clara, CA, USA, 2012) at $1 \mathrm{kHz}$ at room temperature. The ferroelectric properties were measured using a ferroelectric analyzer (Radiant Precision PremierII, Radiant Technologies Inc., Albuquerque, NM, USA, 2005) at room temperature. For the piezoelectric constant $\left(d_{33}\right)$ test, the specimens were poled at room temperature in silicone oil under an applied electric field of $1280 \mathrm{kV} / \mathrm{mm}$ for $15 \mathrm{~min}$. The piezoelectric constant was measured using a quasistatic meter (ZJ-6A, Institute of Acoustics Academic Sinica, Beijing, China, 2005). The element analysis was performed using the ICP-MS (NexION 350D, PerkinElmer, Waltham, MA, USA, 2017) after the samples were dissolved in a mixture of concentrated nitric acid and hydrofluoric acid. In order to calibrate the errors of the quantitative analysis, blank experiments were used before the element analysis.

\section{Results and Discussion}

\section{1. $R O-X R D$}

The RO-XRD patterns of the PMN-PT sample are shown in Figure 3. Two strong peaks were observed at $22.88^{\circ}$ and $35.09^{\circ}$ and there were no other diffraction peaks between them, indicating that the sample is a single crystal. Based on the fixed angle $\varphi$ between the two crystal planes, the oriented direction of one crystal plane can be determined by the other [25,26]. In this study, the (211), (220) and (222) crystal planes were selected to calculate the orientation of the samples according to the following equation $[27,28]$ :

$$
\varphi=\frac{\theta_{2}-\theta_{1}}{2}
$$

where $\theta_{1}$ and $\theta_{2}$ are the degrees of the strong diffraction peaks, respectively. The calculated results show the crystal plane perpendicular to the axial direction is (432). Along the axial direction, the crystal plane belongs to $\{771\}$.

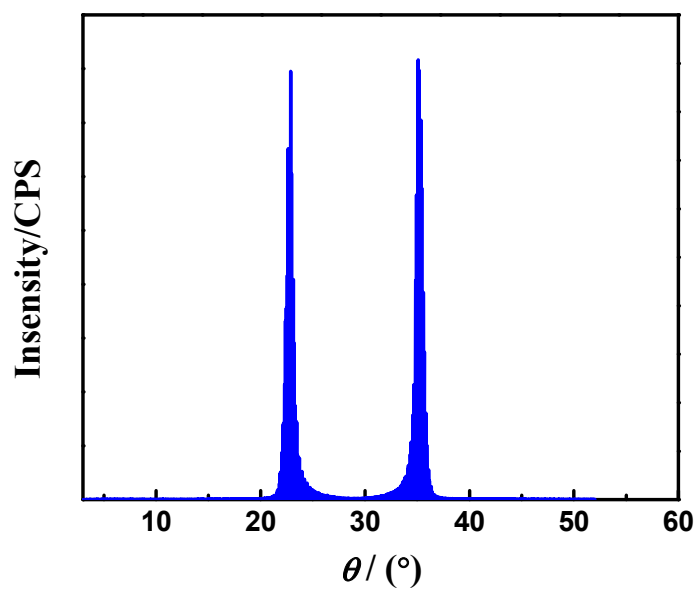

Figure 3. The RO-XRD pattern with $2 \theta=56^{\circ}$ of the PMN-32PT crystal.

\subsection{Axis Distribution}

The distribution of elements along the axial direction for the PMN-32PT single crystals is shown in Figure 4. Obviously, the Ti content exhibits an increasing trend along the axial direction from the bottom to the top. On the other hand, the content of the $\mathrm{Nb}$ and $\mathrm{Mg}$ decreases from the bottom to the top. The variations of the mass fraction of the $\mathrm{Nb}$ and $\mathrm{Mg}$ are calculated to be about $2.29 \%$ and $0.97 \%$, respectively. The segregation during the growth of the PMN-PT single crystals is responsible for the variation of the elements [29]. 


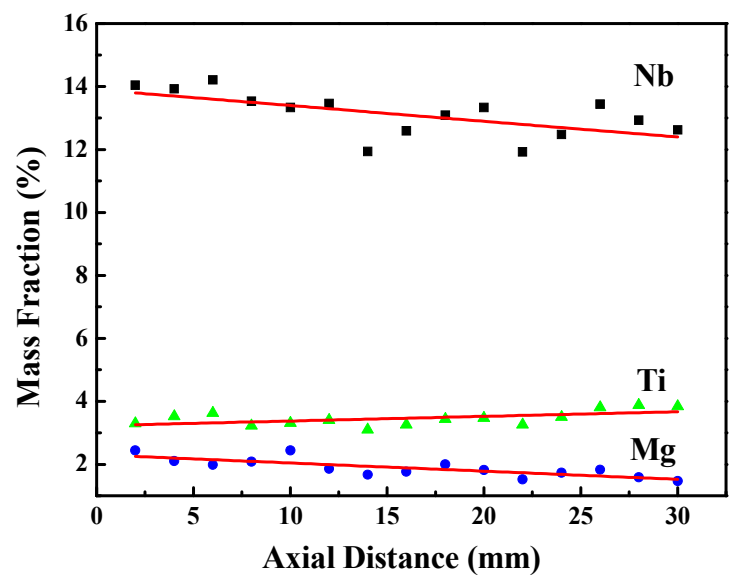

Figure 4. The composition distribution along the axis of the PMN-32PT: points represent the experimental data and solid lines represent the fitting.

Generally, the segregation of the element depends on its the effective segregation coefficient $k$ during the crystal growth process, which can be obtained from the following equation [30]:

$$
C_{s}=k C_{0}(1-f)^{(k-1)}
$$

where $C_{S}$ and $C_{0}$ are the concentrations of the solid and initial melt, respectively, and $f$ is the fraction of the melt solidified corresponding to $C_{S}$. Normally, as the effective segregation coefficient is less than $1(k<1)$, the element content displays an increasing tendency along the axial direction from the bottom to the top. As the effective segregation coefficient is more than $1(k>1)$, the element content shows a decreasing tendency from the bottom to the top of the crystal. In this work, the effective segregation coefficients $k$ are 1.20, 1.03 and 0.82 for $\mathrm{Mg}, \mathrm{Nb}$ and Ti, respectively. The $k$ for Ti is slightly lower than that obtained by Benayad [23] in a PMN-40PT system $(k=0.849)$ and Zawilski [24] in a PMN-35PT system $(k=0.84)$, which is attributed to the slower solidification rate of the present work. Table 1 provides the molar percentages of $\mathrm{Mg}, \mathrm{Nb}$ and $\mathrm{Ti}$ along the axial direction of the crystal from the bottom to the top.

Table 1. The variation of composition from the bottom to the top.

\begin{tabular}{cccc}
\hline Distance(mm) & Mg (mol\%) & Nb (mol\%) & Ti (mol\%) \\
\hline $0-2$ & $31.40 \pm 0.16$ & $47.11 \pm 0.22$ & $21.49 \pm 0.38$ \\
$2-4$ & $28.31 \pm 0.28$ & $48.12 \pm 0.58$ & $23.57 \pm 0.76$ \\
$4-6$ & $26.02 \pm 0.14$ & $49.44 \pm 0.28$ & $24.54 \pm 0.42$ \\
$6-8$ & $28.69 \pm 0.01$ & $48.77 \pm 0.04$ & $22.55 \pm 0.06$ \\
$8-10$ & $32.52 \pm 0.24$ & $45.53 \pm 0.34$ & $21.95 \pm 0.58$ \\
$10-12$ & $26.09 \pm 0.10$ & $49.58 \pm 0.19$ & $24.32 \pm 0.29$ \\
$12-14$ & $25.91 \pm 0.03$ & $49.23 \pm 0.06$ & $24.85 \pm 0.09$ \\
$14-16$ & $25.96 \pm 0.26$ & $49.34 \pm 0.49$ & $24.69 \pm 0.75$ \\
$16-18$ & $28.03 \pm 0.25$ & $47.65 \pm 0.44$ & $24.32 \pm 0.69$ \\
$18-20$ & $25.72 \pm 0.19$ & $48.86 \pm 0.36$ & $25.40 \pm 0.55$ \\
$20-22$ & $23.76 \pm 0.21$ & $49.89 \pm 0.45$ & $26.35 \pm 0.66$ \\
$22-24$ & $25.42 \pm 0.01$ & $48.29 \pm 0.02$ & $26.29 \pm 0.03$ \\
$24-26$ & $25.35 \pm 0.19$ & $48.17 \pm 0.36$ & $26.47 \pm 0.55$ \\
$26-28$ & $23.13 \pm 0.14$ & $48.56 \pm 0.28$ & $28.31 \pm 0.42$ \\
$28-30$ & $21.47 \pm 0.23$ & $49.37 \pm 0.53$ & $29.16 \pm 0.78$ \\
Stoichiometry & 22.67 & 45.33 & 32.00 \\
\hline
\end{tabular}

The mole fractions of the $\mathrm{PMN}\left(\mathrm{Pb}\left(\mathrm{Mg}_{1 / 3} \mathrm{Nb}_{2 / 3}\right) \mathrm{O}_{3}\right)$ and $\mathrm{PT}$ for different samples calculated from the ICP-MS data are shown in Figure 5. The PMN content decreases along the axial direction from the bottom to the top, while the PT content increases from $21 \mathrm{~mol} \%$ to $29 \mathrm{~mol} \%$, which is consistent with 
that of the previous reports [22-24]. These results can be explained by the phase diagram of PMN-PT and the solidification law of the binary solid solution as follows: the PMN crystallizes firstly from the melt because of the higher freezing point of the PMN, which results in the higher content of the PMN at the bottom and the higher PT content in the liquid.

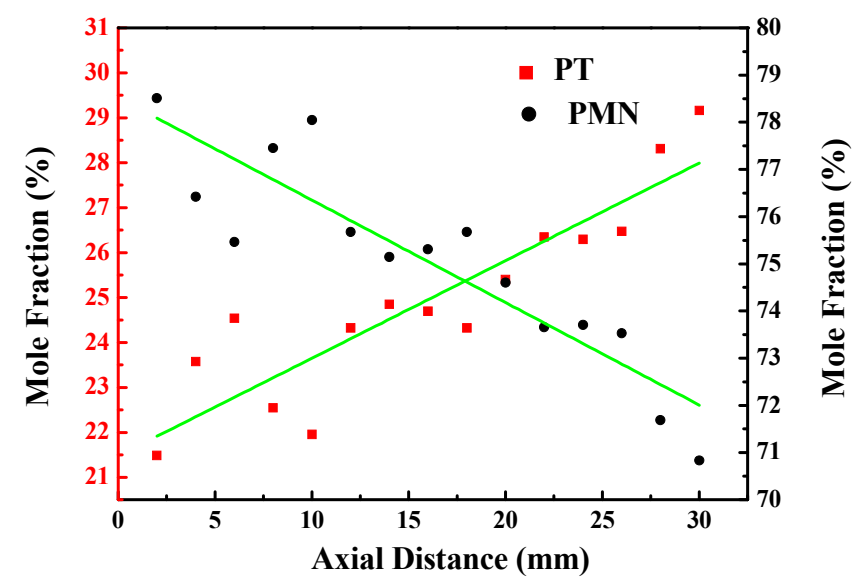

Figure 5. The distribution of the PMN and PT molar fractions along the axial direction: points represent the experimental data and solid lines represent the fitting.

The distribution of the molar ratio $\mathrm{Nb} / \mathrm{Mg}$ along the axial direction is shown in Figure 6. It is seen that the molar ratio $\mathrm{Nb} / \mathrm{Mg}$ exhibits an increasing trend from the bottom to the top. The molar ratio $\mathrm{Nb} / \mathrm{Mg}$ fluctuates greatly at the initial stage of the crystal growth. During the crystal growth, it approaches to 2 in the middle part, and even $>2$ at the top boule. Theoretically, there are two $\mathrm{Nb}^{5+}$ near a $\mathrm{Mg}^{2+}$ in the lattice or melt to balance the valence state [31], namely $\left(\mathrm{Mg}_{1 / 3} \mathrm{Nb}_{2 / 3}\right)^{4+}$. However, $\mathrm{Nb}^{5+}$ and $\mathrm{Mg}^{2+}$ in the actual lattice occupancy are not completely subject to theory due to the segregation.

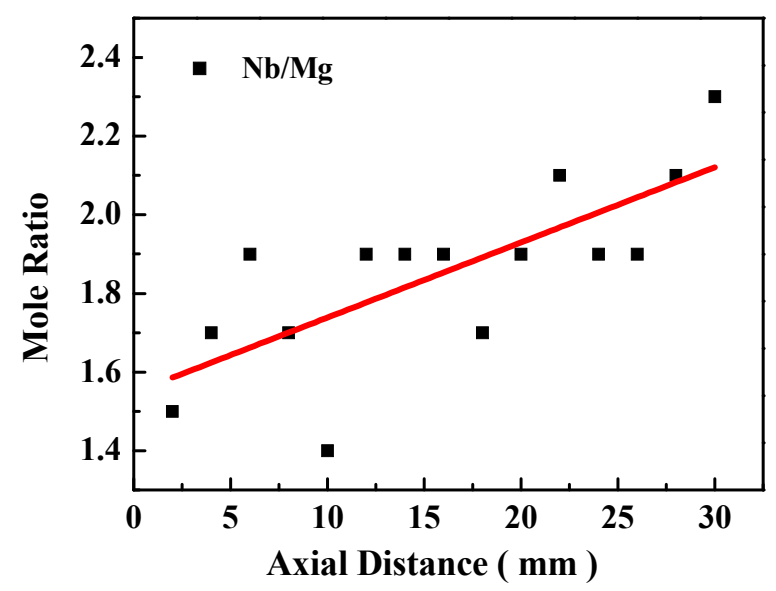

Figure 6. The molar ratio of $\mathrm{Nb}$ and $\mathrm{Mg}$ along the axial direction: points represent the experimental data and dashed lines represent the fitting.

The measured distance dependence of the electrical properties for the specimens along the axial direction is shown in Figure 7. From Figure 7a, we can see the permittivity firstly decreases at the bottom of the crystal and then tends to stabilize at the middle of the crystals. In addition, a sharp rise process for the dielectric constant is observed at the top. The distribution of dielectric loss exhibits a similar tendency, except for the sharp decrease at the top. The sharp variation of the dielectric properties at the top could originate from the presence of cracks. The piezoelectric constant $d_{33}$ increases gradually from $350 \mathrm{pC} / \mathrm{N}$ to $850 \mathrm{pC} / \mathrm{N}$ along the axial direction from the bottom to the top, as shown in Figure $7 \mathrm{~b}$. The coercive field $E_{\mathrm{c}}$ and remnant polarization $P_{\mathrm{r}}$ verse the measured 
distance for the PMN-32PT crystals are shown in Figure 7c,d. It is seen that the coercive field at room temperature fluctuates from $2 \mathrm{kV} / \mathrm{cm}$ to $3 \mathrm{kV} / \mathrm{cm}$ along the axial direction of the crystal. The remnant polarization of the crystal increases gradually except for some fluctuations from the bottom to the top. These results indicate that the segregation affects the electric properties dominantly in the PMN-PT single crystal grown by Bridgman method. In Figures 4 and $7 \mathrm{a}$, it is obvious that the variation tendency of Ti content along the axial direction is opposite to that of the dielectric properties. Differently, the variations of the piezoelectric coefficient and remnant polarization are consistent with that of the PT content, as shown in Figures 5 and $7 \mathrm{~b}$,d. It is well known that it is multi-phase coexistence at the MPB composition for PMN-PT, in which the spontaneous polarization orientations increase. Therefore, the switch of domains and the motion of domain walls are easy under the external electric field, which makes it beneficial to obtain the ultrahigh piezoelectric constant and remnant polarization. The PT content increases gradually and approaches the MPB composition which is the reason for the increase of the piezoelectric coefficient and remnant polarization along the axial direction.

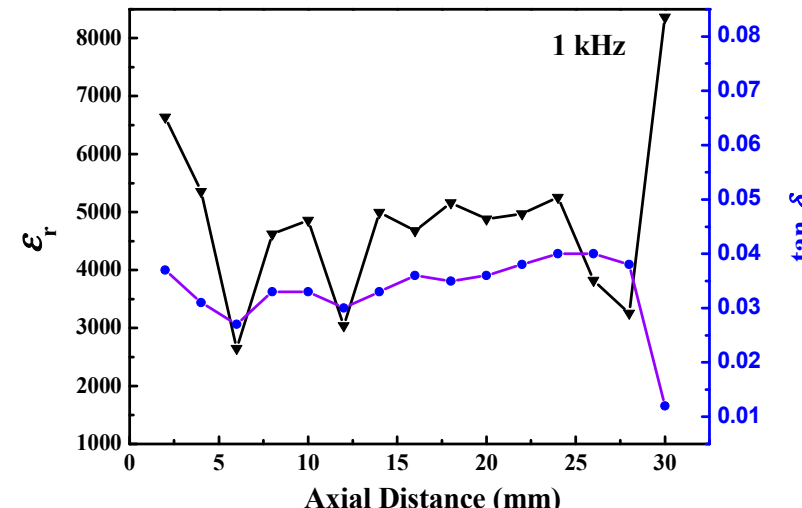

(a)

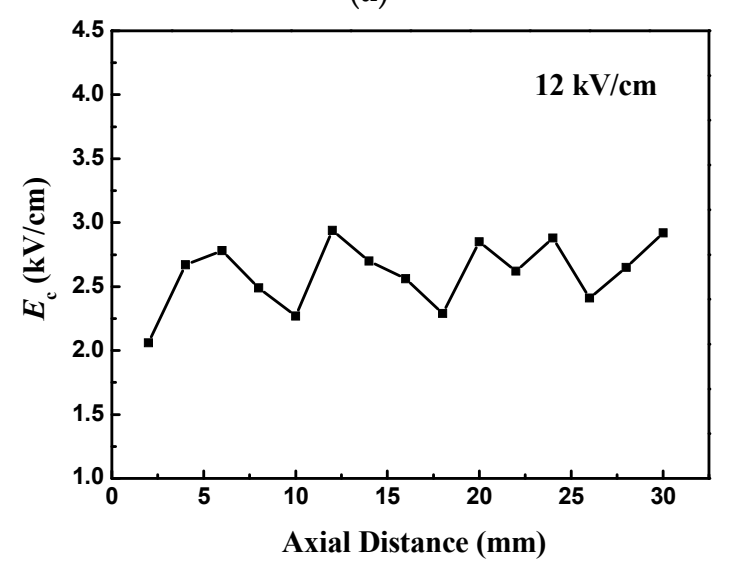

(c)

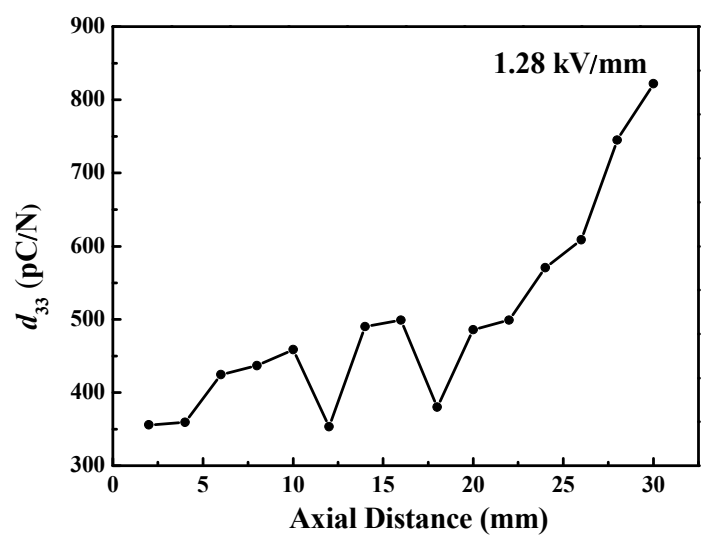

(b)

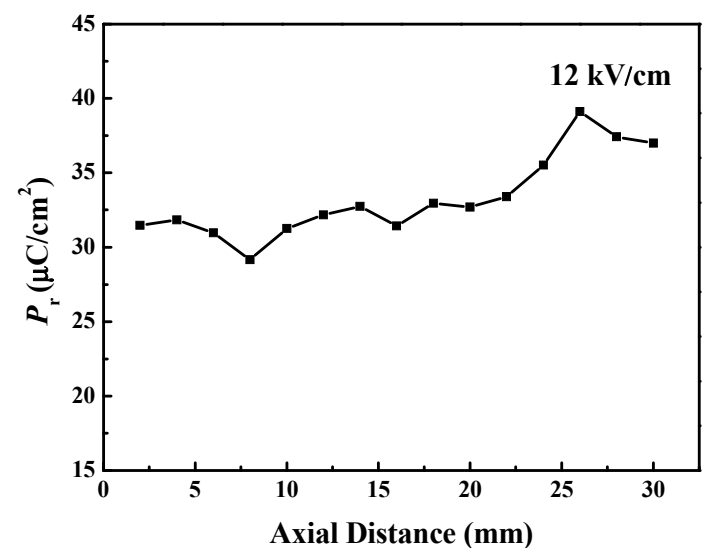

(d)

Figure 7. The variation of the electric properties along the axial direction: (a) the variation of the permittivity $\varepsilon$ and loss tan $\delta$ at $1 \mathrm{kHz}$; (b) the variation of the piezoelectric constant $d_{33}$ poled under $1.28 \mathrm{kV} / \mathrm{mm}$; (c) the variation of the coercive field $E_{\mathrm{c}}$; (d) the variation of the remnant polarization $P \mathrm{r}$.

\subsection{Radial Distribution}

The mass fraction of different elements in a PMN-32PT single crystal along the radial direction is calculated and plotted in Figure 8. It is demonstrated that the $\mathrm{Nb}$ and $\mathrm{Mg}$ content increases by $0.71 \%$ $0.54 \%$, respectively. By contrast, the content of $\mathrm{Ti}$ is relatively stable and increases only by $0.18 \%$. The segregation of the radial direction is attributed to an uneven growth interface and the convection near growth interface [32-35], which is different from the segregation of the axial direction caused by the solute redistribution. 


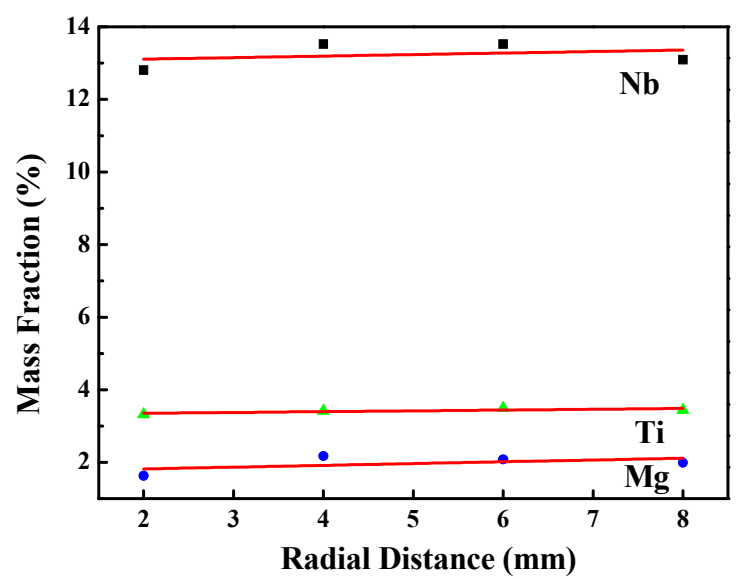

Figure 8. The composition distribution along the radial direction of PMN-32PT: points represent experimental data and the solid lines represent the fitting.

The variation of PMN and PT along the radial direction are presented in Figure 9. The mole fraction of PT nearly remains a constant of $24 \%$, which means that PT is insensitive to the component segregation in the radial direction. Figure 10 illustrates the variation of $\mathrm{Nb} / \mathrm{Mg}$ along the radial direction. The value decreases firstly and then increases slightly.

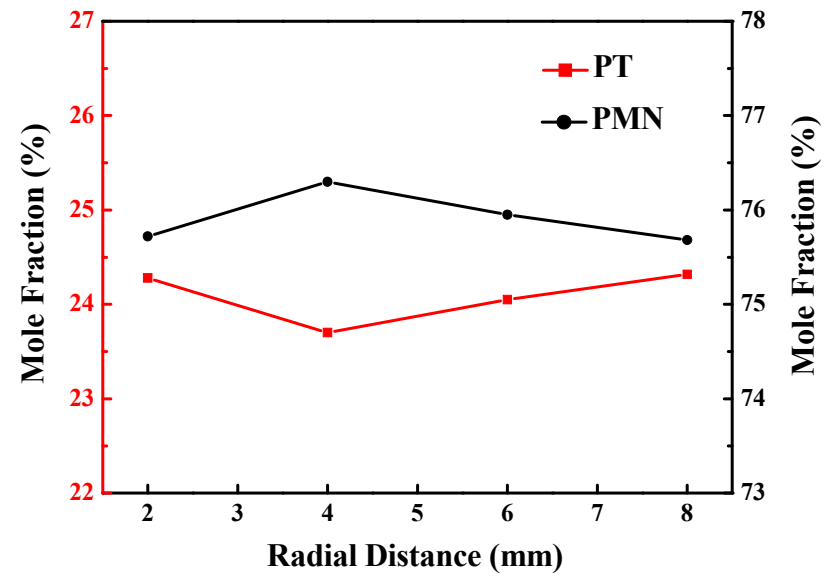

Figure 9. The distribution of PMN and the PT molar fraction along the radial direction.

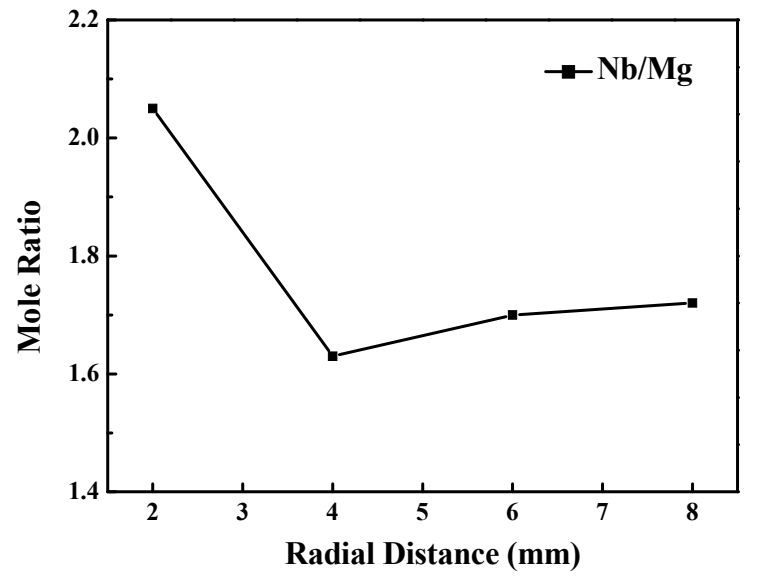

Figure 10. The distribution of the molar ratio of $\mathrm{Nb}$ and $\mathrm{Mg}$ along the radial direction.

The measured distance dependence of the electrical properties for the specimens along the radial direction is shown in Figure 11. The permittivity and piezoelectric constant decrease firstly and then 
increase from the sample $\mathrm{X} 1$ to $\mathrm{X} 4$, which are similar to that of $\mathrm{Nb} / \mathrm{Mg}$ as shown in Figures 10 and $11 \mathrm{a}, \mathrm{b}$. The coercive field increases firstly and then decreases, which varies from the range of $2 \mathrm{kV} / \mathrm{cm}$ to $3 \mathrm{kV} / \mathrm{cm}$ shown in Figure 11c. The remnant polarization is almost maintained at $30-33 \mu \mathrm{C} / \mathrm{cm}^{2}$. The relationship among the permittivity, piezoelectric constant and remnant polarization of the radial samples are basically obedient to the formula reported in the literature: $d_{33}=2 \varepsilon_{0} \varepsilon_{\mathrm{r}} P_{\mathrm{r}} Q_{11}[13,36]$. The dependence of the dielectric constant, piezoelectric constant and coercive field on $\mathrm{Nb} / \mathrm{Mg}$ can be explained as follows: as the $\mathrm{Nb} / \mathrm{Mg}$ decreases, the concentration of the oxygen vacancies increases in the lattice, which pinches the domain and restrains the switch of the domain. As a result, the coercive field increases and the dielectric constant and piezoelectric constant decrease; and vice versa.

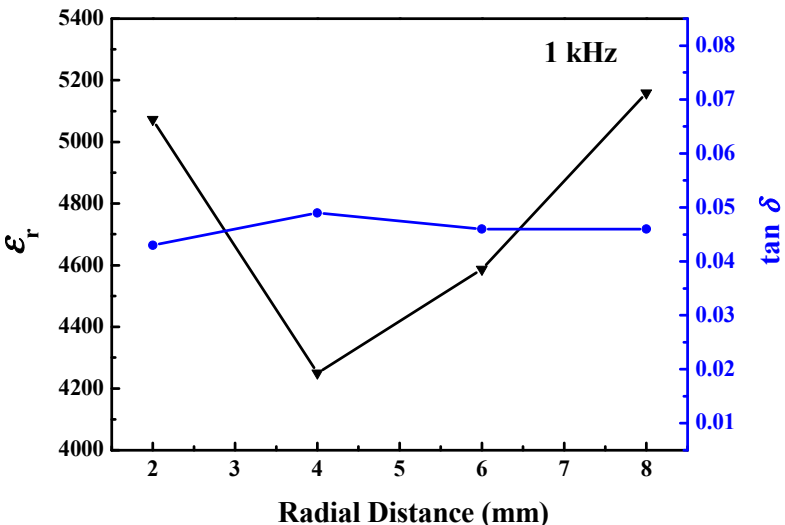

(a)

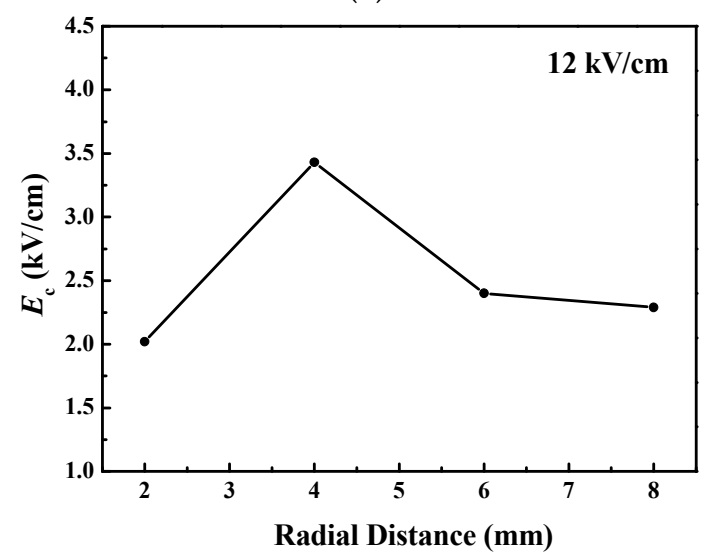

(c)

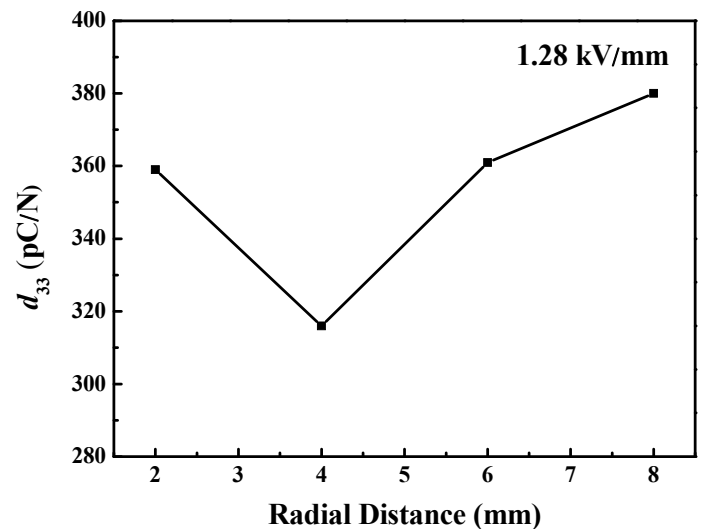

(b)

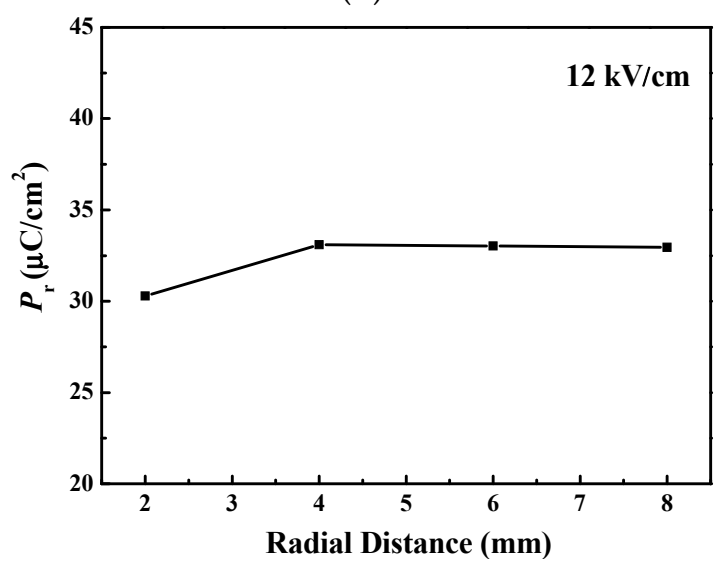

(d)

Figure 11. The variation of the electric properties along the radial direction: (a) the variation of permittivity $\varepsilon$ and loss tan $\delta$ at $1 \mathrm{kHz}$; (b) the variation of the piezoelectric constant $d_{33}$ poled under $1.28 \mathrm{kV} / \mathrm{mm}$; (c) the variation of the coercive field $E_{\mathrm{c}}$; (d) the variation of the remnant polarization $P \mathrm{r}$.

\section{Conclusions}

The single crystal with the nominal compositional PMN-32PT was grown using the Bridgman method. The distribution of the elements along the axial direction could be described by the effective segregation coefficient $k$. The effective segregation coefficients $k$ were $1.20,1.03$ and 0.82 for $\mathrm{Mg}, \mathrm{Nb}$ and Ti, respectively. The relationship between the composition and electrical properties of the PMN-PT crystals was investigated. It was indicated that the piezoelectric constant and remnant polarization were consistent with the distribution of PT along the axial direction. The electrical properties were attributed to the distribution of the $\mathrm{Nb}$ and $\mathrm{Mg}$ along the radial direction.

Author Contributions: Writing-review \& editing, Z.X.; writing-original draft, S.W.; formal analysis, P.F.; X.L.; investigation, W.L.; data curation, A.H. 
Funding: This work was supported by the National Natural Science Foundation of China (Grant No. 51472197), the Key Laboratory of Optoelectronic Materials Chemistry Physics, Chinese Academy of Science (Grant No. 2016DP173016) and and Foundamental Research Foundation of XATU of china (Grant No. XAGDXJJ16020).

Conflicts of Interest: The authors declare no conflict of interest.

\section{References}

1. Xue, A.X.; Fang, C.; Wang, C.; Jia, Y.M.; Liu, Y.S.; Luo, H.S. Uniaxial stress-induced ferroelectric depolarization in $<001>$-oriented $0.72 \mathrm{~Pb}\left(\mathrm{Mg}_{1 / 3} \mathrm{Nb}_{2 / 3}\right) \mathrm{O}_{3}-0.28 \mathrm{PbTiO}_{3}$ single crystal. J. Alloys Compd. 2015, 647, 14-17. [CrossRef]

2. Li, Z.R.; Xu, Z.; Xi, Z.Z.; Cao, L.H.; Yao, X. Dielectric loss anomalies of 0.68PMN-0.32PT single crystal and ceramics at cryogenic temperature. J. Electroceram. 2008, 21, 279-282. [CrossRef]

3. Wang, Z.; Zhang, R.; Sun, E.W.; Cao, W.W. Temperature dependence of electric-field-induced domain switching in $0.7 \mathrm{~Pb}\left(\mathrm{Mg}_{1 / 3} \mathrm{Nb}_{2 / 3}\right) \mathrm{O}_{3}-0.3 \mathrm{PbTiO}_{3}$ single crystal. J. Alloys Compd. 2012, 527, 101-105. [CrossRef] [PubMed]

4. Sun, E.W.; Cao, W.W. Relaxor-based ferroelectric single crystals: Growth, domain engineering, characterization and applications. Prog. Mater. Sci. 2014, 65, 124-210. [CrossRef] [PubMed]

5. Li, F.; Zhang, S.; Xu, Z.; Wei, X.Y.; Luo, J.; Shrout, T.R. Composition and phase dependence of the intrinsic and extrinsic piezoelectric activity of domain engineered $(1-x) \mathrm{Pb}\left(\mathrm{Mg}_{1 / 3} \mathrm{Nb}_{2 / 3}\right) \mathrm{O}_{3-} x \mathrm{PbTiO}_{3}$ crystals. J. Appl. Phys. 2010, 108, 074106. [CrossRef] [PubMed]

6. Guerra, J.D.L.S.; Lente, M.H.; Eiras, J.A. Non-linear dielectric properties in based-PMN relaxor ferroelectrics. J. Eur. Ceram. Soc. 2017, 27, 4033-4036. [CrossRef]

7. Zhou, Q.F.; Lam, K.H.; Zheng, H.R.; Qiu, W.B.; Shung, K.K. Piezoelectric single crystal ultrasonic transducers for biomedical applications. Prog. Mater. Sci. 2014, 66, 87-111. [CrossRef]

8. Shkuratov, S.I.; Baird, J.; Antipov, V.G.; Talantsev, E.F.; Chase, J.B.; Hackenberger, W.; Luo, J.; Jo, H.R.; Lynch, C.S. Ultrahigh energy density harvested from domain-engineered relaxor ferroelectric single crystals under high strain rate loading. Sci. Rep. 2017, 7, 46758. [CrossRef]

9. Guo, M.S.; Dong, S.X.; Ren, B.; Luo, H.S. A double-mode piezoelectric single-crystal ultrasonic micro-actuator. IEEE Trans. Ultrason. Ferroelectr. Freq. Control 2010, 57, 2596-2600.

10. Xu, G.S.; Luo, H.S.; Wang, P.C.; Xu, H.Q.; Yin, Z.W. Ferroelectric and piezoelectric properties of novel relaxor ferroelectric single crystals PMNT. Chin. Sci. Bull. 2000, 45, 491-495. [CrossRef]

11. Tian, J.; Han, P.D. Crystal growth and property characterization for PIN-PMN-PT ternary piezoelectric crystals. J. Adv. Dielectr. 2014, 4, 1350027. [CrossRef]

12. Tian, J.; Han, P.D.; Huang, X.L.; Pan, H.X.; Carroll, J.F.; Payne, D.A. Improved stability for piezoelectric crystals grown in the lead indium niobate-lead magnesium niobate-lead titanate system. Appl. Phys. Lett. 2007, 91, 222903. [CrossRef]

13. Li, F.; Lin, D.B.; Chen, Z.B.; Cheng, Z.X.; Wang, J.L.; Li, C.C.; Xu, Z.; Huang, Q.W.; Liao, X.Z.; Chen, L.Q.; et al. Ultrahigh piezoelectricity in ferroelectric ceramics by design. Nature. Mater. 2018, 17, 349-354. [CrossRef] [PubMed]

14. Xu, J.L.; Deng, H.; Zeng, Z.; Zhang, Z.; Zhao, K.Y.; Chen, J.W.; Nakamori, N.M.; Wang, F.F.; Ma, J.P.; $\mathrm{Li}$, X.B.; et al. Piezoelectric performance enhancement of $\mathrm{Pb}\left(\mathrm{Mg}_{1 / 3} \mathrm{Nb}_{2 / 3}\right) \mathrm{O}_{3}-0.25 \mathrm{PbTiO}_{3}$ crystals by alternating current polarization for ultrasonic transducer. Appl. Phys. Lett. 2018, 112, 182901. [CrossRef]

15. Wang, D.; Yuan, G.L.; Luo, H.S.; Li, J.F.; Viehland, D.; Wang, Y.J. Structural origin of room temperature poling enhanced piezoelectricity in modified $\mathrm{Pb}\left(\mathrm{Mg}_{1 / 3} \mathrm{Nb}_{2 / 3}\right) \mathrm{O}_{3}-30 \% \mathrm{PbTiO}_{3}$ crystals. J. Am. Ceram. Soc. 2017, 100, 4938-4944. [CrossRef]

16. Jiao, S.; Tang, Y.X.; Zhao, X.Y.; Wang, T.; Duan, Z.H.; Wang, F.F.; Sun, D.Z.; Luo, H.S.; Shi, W.Z. Growth and electrical properties of epitaxial $0.7 \mathrm{~Pb}\left(\mathrm{Mg}_{1 / 3} \mathrm{Nb}_{2 / 3}\right) \mathrm{O}_{3}-0.3 \mathrm{PbTiO}_{3}$ thin film by pulsed laser deposition. J. Mater. Sci. 2018, 29, 6779-6784. [CrossRef]

17. Li, F.; Zhang, S.J.; Yang, T.N.; Xu, Z.; Zhang, N.; Liu, G.; Wang, J.L.; Wang, J.L.; Cheng, Z.X.; Ye, Z.G.; et al. The origin of ultrahigh piezoelectricity in relaxor-ferroelectric solid solution crystals. Nat. Common. 2016, 7, 13807. [CrossRef] 
18. Hu, W.H.; Xi, Z.Z.; Fang, P.Y.; Long, W.; Li, X.J.; Bu, Q.Q. A novel poling technique to obtain excellent piezoelectric properties of $\mathrm{Pb}\left(\mathrm{Mg}_{1 / 3} \mathrm{Nb}_{2 / 3}\right) \mathrm{O}_{3}-0.32 \mathrm{PbTiO}_{3}$ single crystals. J. Mater. Sci. Mater. Electron. 2015, 26, 3282-3286. [CrossRef]

19. He, A.G.; Xi, Z.Z.; Li, X.J.; Long, W.; Fang, P.Y.; Zhao, J.; Yu, H.N.; Kong, Y.L. Optical properties of Ho ${ }^{3+}$ - and $\mathrm{Ho}^{3+} / \mathrm{Yb}^{3+}$-modified PSN-PMN-PT crystals. Mater. Lett. 2018, 219, 64-67. [CrossRef]

20. Long, W.; Chu, X.; Xi, Z.Z.; Fang, P.Y.; Li, X.J.; Cao, W.W. Growth and property enhancement of $\mathrm{Er}^{3+}$-doped $0.68 \mathrm{~Pb}\left(\mathrm{Mg}_{1 / 3} \mathrm{Nb}_{2 / 3}\right) \mathrm{O}_{3}-0.32 \mathrm{PbTiO}_{3}$ single crystal. J. Rare. Earth. 2018, 36, 832-837. [CrossRef]

21. Xi, Z.Z.; He, A.G.; Fang, P.Y.; Li, X.J.; Long, W. Electric and optical properties of $\mathrm{Er}^{3+}-\mathrm{and}^{3+} \mathrm{Er}^{3+} / \mathrm{Yb}^{3+}-$ modified PSN-PMN-PT crystals. J. Alloys Compd. 2017, 722, 375-380. [CrossRef]

22. Luo, H.S.; Xu, G.S.; Xu, H.Q.; Wang, P.C.; Yin, Z.W. Compositional homogeneity and electrical preperties of lead magnesium niobate titanate single crystals grown by a Modified Bridgman technique. J. Appl. Phys. 2000, 39, 5581-5585. [CrossRef]

23. Benayad, A.; Sebald, G.; Lebrun, L.; Guiffard, B.; Pruvost, S.; Guyomar, D.; Beylat, L. Segregation study and segregation modeling of $\mathrm{Ti}$ in $\mathrm{Pb}\left[\left(\mathrm{Mg}_{1 / 3} \mathrm{Nb}_{2 / 3}\right)_{0.60} \mathrm{Ti}_{0.40}\right] \mathrm{O}_{3}$ single crystal grown by Bridgman method. Mater. Res. Bull. 2006, 41, 1069-1076. [CrossRef]

24. Zawilski, K.T.; Custodio, M.C.C.; Demattei, R.C.; Lee, S.G.; Monteiro, R.G.; Odagawa, H.; Feigelson, R.S. Segregation during the vertical Bridgman growth of lead magnesium niobate-lead titanate single crystals. J. Cryst. Growth 2003, 258, 353-367. [CrossRef]

25. Guo, Z.Q.; Fu, T.; Fu, H.Z. Crystal Orientation Measured by XRD and Annotation of the Butterfly Diagram. Mater. Charact. 2000, 44, 431-434. [CrossRef]

26. Guo, Z.Q.; Jin, L.; Li, F.; Bai, Y. Applications of the rotating orientation XRD method to oriented materials. J. Appl. Phys. D 2009, 42, 012001. [CrossRef]

27. Guo, Z.Q.; Fu, T.; Wang, N.; Fu, H.Z. A sample XRD method for determining crystal orientation and its distribution. J. Inorg. Mater. 2002, 17, 460-464.

28. Guo, Z.Q.; Li, F.; Xu, Z. Application of new equipment to determine the orientation of single crystal by XRD. Lab. Sci. 2011, 14, 92-96.

29. Zhang, Y.Y.; Li, X.B.; Liu, D.A.; Zhang, Q.H.; Wang, W.; Ren, B.; Lin, D.; Zhao, X.Y.; Luo, H.S. The compositional segregation, phase structure and properties of $\mathrm{Pb}\left(\operatorname{In}_{1 / 2} \mathrm{Nb}_{1 / 2}\right) \mathrm{O}_{3}-\mathrm{Pb}\left(\mathrm{Mg}_{1 / 3} \mathrm{Nb}_{2 / 3}\right) \mathrm{O}_{3}-\mathrm{PbTiO}_{3}$ single crystal. J. Cryst. Growth 2011, 318, 890-894. [CrossRef]

30. Zhang, S.J.; Li, F. High performance ferroelectric relaxor- $\mathrm{PbTiO}_{3}$ single crystals: Status and perspective. J. Appl. Phys. 2012, 111, 031301. [CrossRef]

31. Song, K.X.; Li, Z.R.; Guo, H.S.; Xu, Z.; Fan, S.J. Compositional segregation and electrical properties characterization of [001]-and [011]-oriented co-growth $\mathrm{Pb}\left(\mathrm{In}_{1 / 2} \mathrm{Nb}_{1 / 2}\right) \mathrm{O}_{3}-\mathrm{Pb}\left(\mathrm{Mg}_{1 / 3} \mathrm{Nb}_{2 / 3}\right) \mathrm{O}_{3}-\mathrm{PbTiO} 3$ single crystal. J. Appl. Phys. 2018, 123, 154107. [CrossRef]

32. Ganaoui, M.E.; Bontoux, P. Gravity effects on solidification: The case of an unsteady melt affecting the growth interface. Adv. Space Res. 1999, 24, 1423-1426. [CrossRef]

33. Volkov, P.K.; Zakharov, B.G.; Serebryakov, Y.A. Numerical and experimental investigations of convection and heat/mass transfer effect in melts on inhomogeneity formation during Ge crystal growth by the Bridgman method. J. Cryst. Growth 1999, 204, 475-486. [CrossRef]

34. Yang, C.; Xu, Q.Y.; Liu, B.C. Study of dendrite growth with natural convection in superalloy directional solidification via a multiphase-field-lattice Boltzmann model. Comp. Mater. Sci. 2019, 158, 130-139. [CrossRef]

35. Antar, B.N. Convective instabilities in the melt for solidifying mercury cadmium telluride. J. Cryst. Growth 1991, 113, 92-102. [CrossRef]

36. Lines, M.E.; Glass, A.M. Principles and Applications of Ferroelectrics and Related Materials; Oxford Univ. Press: Oxford, UK, 1977.

(C) 2019 by the authors. Licensee MDPI, Basel, Switzerland. This article is an open access article distributed under the terms and conditions of the Creative Commons Attribution (CC BY) license (http:/ / creativecommons.org/licenses/by/4.0/). 